\title{
Por uma educação antropológica: comparando as idéias de Bronislaw Malinowski e Paulo Freire
}

\author{
Mauricio Rodrigues de Souza \\ Universidade Federal do Pará, Departamento de Psicologia Social e Escolar
}

\section{Introdução}

Embora ainda pouco explorado pela comunidade acadêmica brasileira, o diálogo entre os campos da antropologia e da educação reveste-se de grande importância e detém uma história antiga, a qual ultrapassa em muito a década de 1970, geralmente mais divulgada quando se coloca em pauta a apropriação do saber antropológico pelos pedagogos. ${ }^{1}$ Como apon-

1 Para maiores detalhes acerca desse processo, uma boa indicação é o trabalho de Valente (1996), preocupado com as deformações e/ou banalizações de um ecletismo que pouco ou nada contribui para o desenvolvimento de ambas as disciplinas. Neste sentido, a autora propõe aos educadores um retorno aos princípios da antropologia como ciência, destacando, entre outros, um ponto em particular. Trata-se da necessária interdependência entre a prática descritiva da pesquisa de campo e a(s) teoria(s) que norteiam os objetivos do pesquisador, as quais não se confundem (ou, pelo menos, não deveriam confundir-se) com as categorias do senso comum, se pretendem fornecer um verdadeiro estranhamento do outro. ta Gusmão (1997), tais contatos começam ainda na transição do século XIX ao XX, com os antropólogos analisando os contextos culturais da aprendizagem e os efeitos das diferenças entre os povos no desenvolvimento da infância e da adolescência.

Com efeito, avança Gusmão (idem), o que essas pesquisas revelaram foi a existência de modos de vida ou sistemas interpretativos que, formalizados por técnicas e rituais específicos, exerciam e ainda exercem considerável influência no tipo de educação (leia-se: no controle social) apresentado por diferentes grupos humanos. Nesse sentido, demonstraram ainda como cultura e educação estão absolutamente imbricadas, incluindo-se aí complexas relações de poder.

Ainda segundo Gusmão (idem), porém, foi alguns anos mais tarde, ao longo das décadas de 1930 e 1940, que as relações entre antropologia e educação ganharam mais força. Aqui a autora chama a nossa atenção para o papel desempenhado por Franz Boas e seus discípulos - como Ruth Benedict ou Margareth Mead -, cujas investidas contra os princípios do evolucionismo cultural possibilitaram uma crítica aos valores liberais que caracterizaram o campo político do século XIX e 
que se refletiam no tipo de pedagogia aplicado na sociedade norte-americana das primeiras décadas do século XX. O que a caracterizava? Exatamente uma organização escolar etnocêntrica, que, eminentemente coercitiva e pouco democrática, dificultava a integração do diferente. Conforme a seguinte passagem:

Boas será um crítico atuante diante do sistema educativo americano, denunciando, entre outras coisas, a ideologia que lhe serve de base, centrada na idéia de liberdade, e sua prática educativa de cunho conformista e coercitivo, visando criar sujeitos sociais adequados ao sistema produtivo segundo um modelo ideologizado de cidadão. Demonstra, através de estudos diretos obtidos no campo educacional, que a escola inexiste como instituição independente e, como tal, não possibilita independência e autonomia dos sujeitos que aí estão. A meta da escola centra-se num aluno-modelo que desconsidera a diversidade da comunidade escolar e, para contê-la, atua de forma autoritária. (idem, p. 15)

O trabalho de Gusmão (idem) cita ainda outros antropólogos que, partilhando da perspectiva de Boas, também detiveram a sua parcela de contribuição no histórico de contatos entre antropologia e educação. Exemplos vêm dos nomes de Melvin Herskovits e Robert Redfield - os quais, entre outras coisas, pesquisaram o papel do educador na mediação de conflitos entre as heranças culturais e as experiências pessoais do alunado -, além de Gilberto Freyre, importante pensador da realidade social brasileira e autor do clássico livro Casa-grande \& senzala.

Pois bem, certamente muito ainda haveria por ser dito caso se optasse por um aprofundamento no desenrolar dessa história. Uma vez, porém, que tal tarefa ultrapassa os interesses deste artigo, guardemos conosco este preâmbulo para com ele avançarmos rumo ao principal objetivo deste trabalho: aproximar as idéias de um antropólogo como Bronislaw Malinowski daquelas outras, sugeridas pela pedagogia de Paulo Freire, para com elas iluminar tarefas da antropologia da educação e da educação na antropologia.

"Mas", deve estar perguntando-se o leitor atento, "como justificar o contraponto entre autores tão distintos?". A resposta a esta questão pode ser buscada de duas maneiras. Primeiro, na própria formação e história de vida de Paulo Freire, ao qual, assim como Malinowski, certamente cabe o adjetivo de "cidadão do mundo", dadas as suas inúmeras viagens (fossem elas espontâneas e respondendo a propostas de trabalho, ou então impostas pelo contexto da ditadura brasileira nas décadas de 1960 e 1970) e, diretamente associado a elas, o contato com diferentes culturas e amplas maneiras de se pensar a vida em sociedade (Gadotti, 1996; Freire, 2003).

Em segundo lugar, tal comparação se revela bastante válida se relembrarmos aqui o princípio básico que imortalizou tanto a pedagogia de Freire quanto a antropologia malinowskiana: o respeito à realidade própria do outro (seja ele um membro das tribos das Ilhas Trobriand ou um habitante da caatinga do Nordeste brasileiro) como condição sine qua non para a produção do conhecimento (Durham, 1986; McLaren \& Leonard, 1996; Freire, 2002). É o que veremos a seguir.

Antes, porém, resta falar um pouco da estrutura do presente artigo, que se desenvolverá em três partes específicas. Primeiro, após a leitura do livro de Malinowski (1976) - hoje clássico da antropologia Argonautas do Pacífico Ocidental, investigará como se apresenta, para esse autor, uma educação do antropólogo. Neste sentido, colocará em evidência as principais idéias do seu texto, baseadas, à primeira vista, em um único preceito fundamental: em defesa do fim do etnocentrismo etnográfico, buscar estudar o diferente em seus próprios meios e encará-lo segundo a lógica da sua própria visão cultural de mundo. Assim, jamais contaminar os encontros com o outro e as análises daí decorrentes com juízos de valor advindos da própria cultura do pesquisador. Eis a mensagem que encerra a primeira parte deste artigo.

Um segundo momento será dedicado especificamente ao livro de Freire (1996), Pedagogia da autonomia que, de leitura bastante agradável, parece condensar boa parte do pensamento desse importante educador. Então, em um processo análogo, esmiuçarei as principais idéias do texto, contidas em precei- 
tos como os seguintes: a) a melhoria pedagógica está necessariamente atrelada ao compromisso social e b) desta forma, urge fazer uma revisão dos conceitos de ensino e aprendizagem, tomados até então como assimilação, e não construção e acesso ao saber. Com isso, finalizo esta segunda parte e também uma primeira parte do trabalho como um todo: o comparar.

Finalmente, em um terceiro momento, retornarei aos textos de Malinowski (1976) e Freire (1996) para, daí sim, contrastá-los em busca de uma educação do antropólogo ou de contribuições da antropologia para a educação, tarefa para a qual contarei ainda com a preciosa ajuda de trabalhos como os de Gusmão (2003) e Valente (2003). Neste sentido, corroborando com o já comentado até aqui, um ponto certamente merece destaque: a necessidade de professores e antropólogos respeitarem sempre o "saber-fazer" comunitário já previamente adquirido por seus respectivos outros, sejam eles alunos ou "nativos". É o que nos diz um certo antropólogo-educador polonês do qual me ocuparei a seguir.

\section{Primeira parte: um educador no Pacífico Ocidental}

Ao iniciar esta breve análise do texto de Malinowski (1976), uma observação faz-se necessária: em se tratando de um trabalho riquíssimo em termos de dados etnográficos e de sugestões para reflexão, evidentemente não tenho aqui a pretensão de abarcar todo o seu conteúdo. Assim, meu olhar estará orientado fundamentalmente para um ponto específico, que é debater um pouco do que se configura, para esse autor, como uma educação do antropólogo. ${ }^{2}$ Embora essa

2 Além do já referido clássico Argonautas do Pacífico Ocidental, indico àquele leitor interessado em se aprofundar em outros aspectos do pensamento de Malinowski um outro livro do etnógrafo polonês editado no Brasil. Trata-se de Uma teoria científica da cultura (Malinowski, 1970). Além dele, duas outras importantes referências podem ser encontradas nos trabalhos de Firth (1960) e Durham (1978). não tenha sido a sua preocupação principal, algumas passagens do livro possuem um cunho bastante didático ao se dirigirem especificamente aos etnógrafos e aos cuidados que estes deveriam ter para a confecção de um bom trabalho de campo. Desta forma, evidenciam ainda as idéias particulares de alguém que recusava ao cientista um papel de suposta neutralidade e, assim, podem nos fornecer algumas pistas úteis. Vamos a elas, então.

Já a introdução do livro aparece recheada de questões de ordem metodológica, mas que de forma alguma estão separadas de um contorno ético. É assim que versam sobre a necessidade da probidade intelectual, algo que, para Malinowski (1976), até então não vinha ocorrendo de maneira satisfatória. ${ }^{3}$ É com esse espírito que pode ser lida a recomendação de que o trabalho etnográfico só tem valor se:

[...] permitir distinguir claramente, de um lado, os resultados da observação direta e das declarações e interpretações nativas e, de outro, as inferências do autor, baseadas em seu próprio bom-senso e intuição psicológica. [...] $\mathrm{Na}$ etnografia, é freqüentemente imensa a distância entre a apresentação final dos resultados da pesquisa e o material bruto das informações coletadas pelo pesquisador através de suas próprias observações, das asserções dos nativos, do caleidoscópio da vida tribal. (p. 22-23)

Note-se desde já a preocupação com o respeito ao outro em seus próprios termos, sem inferências

\footnotetext{
3 Temos aqui uma crítica à chamada "Escola evolucionista"
} que precedeu os trabalhos de Malinowski, a qual, embora composta por eruditos representantes, se preocupava em obter conclusões bastante generalistas e, para os padrões da antropologia contemporânea, além de carecer de uma base empírica convincente, refletia certos posicionamentos etnocêntricos dos seus teóricos, baseados na noção de que a sociedade européia se situaria no topo de uma suposta escala evolutiva da humanidade. Para maiores informações acerca desse período do pensamento antropológico, sugiro a consulta de clássicos da história da disciplina, como aqueles de Harris (1968) e Voget (1975). 
etnocêntricas. Esse é, seguramente, um dos temas principais do livro e um marco histórico no desenvolvimento da disciplina antropológica. Contudo, não deixa de ser interessante notar também como, para além dessa perspectiva da clara separação entre reflexões pessoais e análise empírica (ou exatamente de acordo com ela), o texto de Malinowski (1976) não tem qualquer "pudor" em revelar que por detrás das suas páginas se encontrava um ser humano também sujeito a angústias, dúvidas e temores: "Passei por fases de grande desânimo, quando então me entregava à leitura de um romance qualquer, exatamente como um homem que, numa crise de depressão e tédio tropical, se entrega à bebida" (p. 23). Destaca-se aqui o resgate da subjetividade do pesquisador em sua relação com esse outro tantas vezes diferente e mesmo desafiador.

É, todavia, ao abordar o tema das dificuldades de comunicação entre dois mundos aparentemente tão distintos (o do "nativo" e o do etnógrafo) que Malinowski (1976) inaugura uma outra categoria que muito me interessa aqui: a da necessidade de observar o em torno, o aparentemente banal e cotidiano como fontes inestimáveis de aprendizado. Eis quando a concretude fornece vida à abstração teórica:

No meu passeio matinal pela aldeia, podia observar detalhes íntimos da vida familiar - os nativos fazendo sua toalete, cozinhando, comendo; podia observar os preparativos para os trabalhos do dia, as pessoas saindo para realizar suas tarefas. [...] O etnógrafo de campo deve analisar com seriedade e moderação todos os fenômenos que caracterizam cada aspecto da cultura tribal sem privilegiar aqueles que lhe causam mais admiração ou estranheza em detrimento dos fatos comuns e rotineiros. (p. 25-28)

Vale lembrar que Malinowski (1976) defendeu sempre e incontinente a necessidade de estarmos junto aos grupos que estudamos, "aprendendo-fazendo", além dos seus costumes, fundamentalmente a sua língua, condição indispensável para uma pesquisa etnográfica que propõe a complementaridade entre o saber científico ("daqui”) e o saber comunitário ("de lá"). Nada mais coerente, portanto, com a premissa ética de tentar ao máximo perceber e respeitar diferentes visões de mundo sem querer lhes impor os nossos próprios valores.

Malinowski (1976) percebeu e mostra-nos aqui o quanto há aspectos da pesquisa que não podem ser analisados somente por critérios quantitativos ou pretensamente objetivos. Com efeito, rejeitando sempre a máscara do cientista "neutro" e separado do "objeto", propõe-nos, pelo contrário, a interação, a relação entre as subjetividades de ambos (pesquisadores e "nativos") como medida efetiva para uma pesquisa verdadeiramente eficiente:

Então, a carne e o sangue da vida nativa real preenchem o esqueleto vazio das construções abstratas. [...] Em outras palavras, há uma série de fenômenos de suma importância que de forma alguma podem ser registrados apenas com o auxílio de questionários ou documentos estatísticos, mas devem ser observados em sua plena realidade. A esses fenômenos podemos dar o nome de os imponderáveis da vida real. [...] nesse tipo de pesquisa, recomenda-se ao etnógrafo que de vez em quando deixe de lado máquina fotográfica, lápis e caderno, e participe pessoalmente do que está acontecendo. Ele pode tomar parte nos jogos dos nativos, acompanhá-los em suas visitas e passeios, ou sentar-se com eles, ouvindo e participando das conversas. (p. 33-35)

É com base nessa concepção - a qual alia a coleta etnográfica de dados à presença do subjetivismo do pesquisador - que Malinowski (1976) adota uma clara posição ética contra o preconceito: "Se ficarmos na ilusão de que o nativo é o filho folgazão e preguiçoso da natureza [...] de modo algum poderemos compreender seus propósitos e os motivos que o levam a executar o kula ou qualquer outro tipo de empreendimento" (p. 58).

Aliás, esse mesmo respeito à alteridade se faz presente em várias outras passagens. Por exemplo, na recomendação, feita por Malinowski (1976), de que o etnógrafo constantemente repense a influência do seu papel no modus vivendi dos grupos que pesquisa, consciência esta necessária para a avaliação de eventuais invasões de espaço. Neste mesmo sentido, 
há ainda a preocupação do etnógrafo polonês quanto à linguagem e aos termos que usamos nesse contato, já que, muitas vezes, a atividade ou o pensamento “deles" não se enquadra nas nossas próprias denominações ou categorias de análise. Assim é que devemos manter sempre em mente:

\section{[...] a longa distância que existe entre a crua declara-} ção nativa e a sua apresentação etnográfica explícita. [...] qualquer que seja a importância de tais textos, eles não são a única nem a mais importante fonte de informações etnográficas. O observador deve ler estes textos considerando o contexto da vida tribal. (p. 331)

Mais do que tudo isso, porém, a grande mensagem de Argonautas do Pacífico Ocidental parece residir na recomendação de que as trocas com o outro não se encerrem em si mesmas. Que sirvam, então, para situarmos a nós mesmos, professores e pesquisadores, como sujeitos éticos, inseridos no mundo e, desta forma, jamais pretensamente "neutros", mas necessariamente engajados na luta por uma sociedade mais justa e baseada no respeito e na complementaridade entre os ditos saberes "técnicos" e "comunitários". Afinal:

Ao captar a visão essencial dos outros [...] estamos contribuindo para alargar a nossa própria visão. Não podemos chegar à sabedoria final socrática de conhecer-nos a nós mesmos se nunca deixarmos os estreitos limites dos costumes, crenças e preconceitos em que todo homem nasceu. [...] E mais: nunca a humanidade civilizada precisou dessa tolerância mais do que agora. (Malinowski, 1976, p. 374)

Guardemos conosco a citação acima. Seu conteúdo reveste-se de suma importância para auxiliar na passagem rumo a uma segunda etapa deste trabalho. Nela serão comparadas as idéias de Malinowski (1976) com aquelas de um outro pensador que também deixou a sua terra natal para se aventurar em diálogos com o mundo permanentemente pautados pelo respeito à alteridade. Trata-se de Paulo Freire. Para tanto, seguindo o exemplo anterior, abordarei em de- talhes um texto específico do educador brasileiro: Pedagogia da autonomia (1996), nosso companheiro a partir de agora.

\section{Segunda parte: um antropólogo na sala de aula}

"A questão da formação docente ao lado da reflexão sobre a prática educativo-progressista em favor da autonomia do ser dos educandos é a temática central em torno de que gira este texto" (Freire, 1996, p. 14). Como se pode notar, é desde o começo do seu livro que Paulo Freire nos brinda com os princípios de uma pedagogia que somente pode ser obtida pela via do respeito ao saber comunitário previamente adquirido pelos estudantes antes da sua inserção na sala de aula. Destarte, segue o nosso autor, torna-se absolutamente urgente a revisão dos conceitos de ensinar e aprender, até então baseados em uma relação hierárquica de transferência do conhecimento.

É dando continuidade a essa perspectiva que Freire (1996) postula o primeiro dos vários "saberes indispensáveis" do que se constituiria, para si, em um verdadeiro processo de ensino-aprendizagem em conjunto. Segundo ele, ensinar não é transmitir conhecimentos, mas criar possibilidades de autonomia e construção em uma via de mão dupla, em que "Quem ensina aprende ao ensinar e quem aprende ensina ao aprender" (p. 25). Aqui, para além da mera replicação, este mesmo aprender aparece também como sinônimo de recriar e refazer em um movimento que pode deflagrar no aprendiz uma inventividade crescente.

Para ser um bom professor, portanto, torna-se necessário saber que a pedra fundamental é a curiosidade, um gatilho para a imaginação e para as emoções. Sempre, porém, fomentando a passagem do "ingênuo" ao metódico o mais democraticamente possível. Nestes termos, uma das qualidades essenciais para o exercício da autoridade docente verdadeiramente democrática é a segurança de um mestre que decide e atua, mas que também sabe respeitar o saber-fazer discente. Afinal, a segurança desse mesmo mestre deve advir da sua sabedoria, e não ser imposta de forma tirânica. 
Com efeito, a incompetência profissional desqualifica uma autoridade que, para ser coerente e democrática, aposta sim na liberdade e instiga a esperança. Falamos aqui de uma liberdade de saber independente, autônoma e construída em conjunto, mas, sobretudo, responsável, pois, se muito insiste Freire (1996) em uma aprendizagem libertária e criativa, esta não deve ser confundida com libertinagem sem limites. $\mathrm{O}$ aluno deve ter o direito de fazer por si, nem que erre. $\mathrm{O}$ erro, porém, deve ser assumido sempre com responsabilidade - aspecto este fundamental a ser trabalhado em sala de aula.

Mais do que com o discente, entretanto, o "ensinar-certo" de Freire (1996) remete o educador a um compromisso consigo mesmo na correspondência entre o discurso que prega em sala de aula e a sua própria prática de vida como sujeito histórico, incompleto, imperfeito e, por isso mesmo, necessariamente mais humanista, engajado e esperançoso. Afinal, como mencionado há pouco, essa necessidade do respeito à autonomia de ser do educando é algo que exige uma prática coerente e baseada no bom senso, na curiosidade e consciência da historicidade do saber em um processo em que a avaliação se dá de todos para com todos, e não só por parte do docente. ${ }^{4}$

\footnotetext{
4 Desta forma, expõe ainda Freire (1996), um verdadeiro
} educador valoriza também as situações informais do ambiente escolar, familiar ou comunitário como fontes ímpares e constantes de aprendizado. Tal perspectiva é partilhada pelo trabalho de Assmann (1998) que, dentre as 13 colocações que faz para uma melhoria da qualidade social e cognitiva da educação, também busca atrelar o conhecimento ao afeto (leia-se: à própria vida). Afinal, para esse educador a pedagogia deve agir sempre como ponte entre processos vitais e cognitivos rumo à dimensão de um saber prazeroso, particular e, assim, flexível; conforme o seguinte trecho: "Proponho que encaremos de frente o perigo de estarmos praticando um verdadeiro apartheid neuronal em relação ao potencial cognitivo dos aprendentes (alunos/as) enquanto não colocarmos no centro da nossa visão pedagógica as experiências de aprendizagem enquanto tais, e não apenas a melhoria do ensino enquanto transmissão instrucional de saberes supostamente já prontos" (Assmann, 1998, p. 19).
Este é, na verdade, um dos pontos sempre recorrentes de um texto que acredita que, em vez da certeza autoritária, a dúvida é seminal no processo do aprendizado. Com isso, acredita também que pensar certo é poder sempre mudar de opinião na busca de um trabalho em conjunto com o aluno que apareça marcado pela assunção de uma condição de ser pensante, criativo e produtor. Predominantemente, porém, um ser político que, para além da teoria, demonstre que ensinar é um testemunho de vida.

É no bojo desses jogos dialógicos e dialéticos que Freire (1996) nos propõe mais um saber fundamental: reconhecer - e, desta forma, combater veementemente - a força da ideologia na formação docente. O alvo aqui é, acima de tudo, o "fatalismo" neoliberal, já que contra uma ética de mercado deve prevalecer sempre aquela outra, própria ao humano. Nesse sentido, avança Freire, se o progresso científico atende mais aos interesses do capital que ao bemestar das pessoas, torna-se absolutamente descartável, o que não significa, é claro, que devamos inibir a pesquisa, mas sim que esta deve ser colocada prioritariamente a serviço da comunidade.

Temos aqui a celebração da grande virtude que reside na diminuição do espaço entre o saber e o fazer. Acreditando nisso é que outro dos preceitos propostos por Freire (1996) para uma educação progressista e digna é aquele que nos diz que pensar certo pressupõe uma vigilância constante sobre os nossos atos e as eventuais (quiçá indeléveis) conseqüências destes nos educandos. Nesse mesmo sentido, segue a recomendação de que nos assumamos eticamente, reconhecendo os condicionamentos aos quais estamos sujeitos, mas também a chance de lutarmos contra eles, pois é dessa consciência que vem uma educação permanente e voltada para a esperança do novo, de um saber eminentemente fundante.

Um projeto como esse só se torna realidade se passarmos a compreender visões de mundo que podem não ser as nossas. Com efeito, mais uma vez ressalta Freire (1996), se é inevitável que o professor trabalhe com certas generalizações, que isso seja feito o máximo possível a partir do saber nativo - aque- 
le do aluno, das classes populares, vinculado, por seu turno, a experiências de socialização prévias ao ingresso na sala de aula. Para ser docente, portanto, fazse mister saber escutar com genuína disponibilidade. Aliás, a mesma que deve ter o educando ante o objeto, despertando, assim, uma curiosidade que, ainda que aparentemente ingênua, pode e deve ser utilizada pelo educador como fundamento do conhecimento epistemológico: "O professor autoritário, que recusa escutar os alunos, se fecha a esta aventura criadora. Nega a si mesmo a participação neste momento de boniteza singular: o da afirmação do educando como sujeito de conhecimento" (p. 141). ${ }^{5}$

Segundo essa ótica, a segurança curiosamente reside na incerteza da incompletude, aqui pensada como uma aliada da esperança. Só a abertura ao mundo roda o moinho da história, e é essa abertura que deve ter o docente à realidade social dos seus alunos, buscando, na medida do possível, vincular o saber "técnico" ao saber-fazer destes últimos. Tudo isso aliado a uma constante preocupação ética, baseada também em conhecimentos outros, como os das leis (expressas e latentes) da comunicação e da ideologia. Fundamentalmente, porém, se trata de educar com paixão, com um conhecimento que não pode ser desvinculado do afeto. Afinal, para Freire (1996), o intelectual não é (ou não deveria ser) frio e arrogante. É sempre gente que lida com outras "gentes" tão históricas e imperfeitas quanto ele, mas nem por isso menos esperançosas e comprometidas com um mundo mais justo.

Tais considerações resumem bem a essência da Pedagogia da autonomia, servindo como um convite para que alcemos novos vôos. Desta feita, rumo às potencialidades ofertadas pelo contraste entre as lições de Malinowski (1976) e Freire (1996). Analise-

5 Entretanto, apressa-se em nos dizer Freire (1996), se essa relação educacional não tem a ver com formalismos preestabelecidos, não implica também falta de método e não serve como desculpa para desleixos no conteúdo ou no didatismo do saber acadêmico. mos, então, de que maneira elas nos auxiliam a pensar em uma educação que se pretenda verdadeiramente antropológica.

\section{À guisa de conclusão: "eus" e "outros" na sala de aula e na pesquisa etnográfica}

Ao iniciar esta última etapa do trabalho, um primeiro ponto a ser destacado é o fato de que tanto para Malinowski (1976) quanto para Freire (1996) a metodologia científica jaz absolutamente inseparável de uma ética de vida. Assim é que ambos nos propõem o resgate do sentimento, dos medos e das paixões de pesquisadores e professores como partes indissociáveis das suas atividades profissionais.

Com esta subjetividade recuperada, acaba o espaço para a pretensão de uma neutralidade científica. Eis mais um aspecto partilhado pela antropologia de Malinowski (1976) e pela pedagogia de Freire (1996), de onde vem a recomendação de jamais negarmos as nossas opções políticas, visando sempre à maior aproximação entre o saber acadêmico e o texto mais amplo da vida, evidenciado nas tradições populares. Logo, o antropólogo e o mestre devem estar dispostos a ouvir, repensando sempre os conceitos que formulam, a relação da academia com a comunidade e, acima de tudo, evitando qualquer reducionismo ou distorção.

É claro que há a premência de conhecer bem a técnica, já que, como vimos em Freire (1996), a incompetência anula a autoridade. Ocorre, porém, que esta última não quer necessariamente dizer frieza, arrogância ou preconceito em relação a saberes que, no seu próprio terreno, também são autênticos. Daí a proposta dos conhecimentos antropológico-pedagógicos não se darem em pedestais, mas sempre na interrelação com esses outros ("nativos" e alunos). Daí também a premissa de, respeitando o saber "ingênuo" das classes populares, buscar ao máximo transformálo em curiosidade epistemológica.

Se, então, damos valor à vida, ao comunitário e ao aparentemente banal, não podemos esquecer-nos da importância que deve ser conferida ao em torno, 
tanto no ensino quanto na pesquisa etnográfica. Desta forma, levando-se em conta ainda a perspectiva de que comunicação não é só fala e escuta, percebe-se a real necessidade de antropólogos e professores conhecerem os alunos e grupos com os quais trabalham não só em momentos específicos - como em um ritual religioso ou no contexto da sala de aula, por exemplo - mas também (e fundamentalmente) nas suas relações sociais mais amplas, inclusive no ambiente doméstico. $\mathrm{O}$ aprendizado, vê-se aqui, também se dá em contextos informais, como festas e encontros, oportunidades ímpares de contato e aprimoramento não só profissional, mas verdadeiramente humano. É a vida completando a teoria no "saber-fazer" de que nos fala Freire (1996). ${ }^{6}$

Com base nesses argumentos, parece que podemos chegar a uma dedução mais ampla. Qual seja, a de que se o aprendizado não está na separação entre teoria e vida, também não está na separação entre "sujeitos" e "objetos" (professores e alunos, pesquisadores e "nativos"), mas sim na relação entre eles. Não se trata, contudo, de uma relação qualquer, já que esta precisa deter um caráter construtivo em que nem o trabalho de campo do etnógrafo, nem tampouco o aprendizado da sala de aula do educador partam de pré-conceitos sobre supostas relações de autoridade ou verticalidade do saber. ${ }^{7}$

Neste ponto, vale a pena insistir no problema da adequação entre alteridade e linguagem, acrescentando às observações de Malinowski (1976) e Freire

6 Como também aponta Brandão (1983), torna-se importante retirar dessas situações o abstrato do concreto, o conhecimento advindo do próprio ofício ou do cotidiano. Nunca, porém, como algo já pronto, mas na qualidade de um processo histórico permanentemente inacabado e aberto ao novo.

7 Se associarmos as idéias de Freire (1996) aos relatos de observações participantes produzidos por antropólogos do quilate de Foote-Whyte (1975), Seeger (1980) ou Guimarães (1985), teremos claros exemplos das grandes possibilidades de o mestre aprender ao ensinar, ao mesmo tempo em que também pode fazêlo o antropólogo, inserindo-se na cultura alheia.
(1996) aquela presente na obra de Geertz (1977) de que a nossa leitura sobre o outro é sempre uma das interpretações possíveis. Tal constatação, por sua vez, nos conduz às seguintes perguntas: quais os problemas dessa tradução de uma cultura diferente para a nossa própria? Ela foi feita por quem e interessa a quem?

Ou seja, devemos ter claro que tanto os textos da sala de aula quanto os da pesquisa antropológica devem abrir espaço a uma polifonia na qual não só mestres e pesquisadores falem, mas também alunos e grupos de qualquer natureza. Com efeito, os trabalhos acadêmicos poderão ser repensados em seu alcance, de forma que, menos voltados para o próprio umbigo, atendam também às demandas da sociedade mais ampla. Afinal, de que adianta estarmos lá, em contato com os "nativos" - alunos ou comunidades carentes, por exemplo -, se não estamos verdadeiramente dispostos a ouvi-los?

Trata-se, portanto, de estabelecermos uma convivência com a alteridade baseada em solidárias relações de eqüidade. Corroborando tal idéia, autoras como Gusmão (2003) e Valente (2003) localizam precisamente aí o desafio da escola contemporânea, já que ser diferente não significa necessariamente ser desigual, e qualquer tentativa de camuflar as particularidades certamente acabará por se revelar autoritária. Neste sentido, urge repensar o que entendemos por cultura e como esta é tomada no interior dos projetos educativos que regem as práticas escolares cotidianas, problematizando assim a visão da escola enquanto agente homogeneizador de um bricolage cultural como o brasileiro. Isso porque:

Nessa condição, o espaço de discussão, de respeito e de vivência da heterogeneidade é bastante reduzido. Por eliminação, só caberia à escola devolver à sociedade brasileira, ou aos diversos segmentos da sociedade civil, a tarefa de coordenar ações educativas não-escolares de promoção e de defesa da diversidade. (Valente, 2003, p. 23-24)

De acordo com essa mesma linha de raciocínio, uma possível relação entre pedagogia e antropologia 
revela-se através da recomendação de que o olhar do educador se estenda para além dos muros da escola, contemplando as construções sociais que, diretamente associadas a relações de poder e exclusão, orientam tanto os diferentes modos de pensar e agir do alunado quanto a própria prática docente. Afinal: "a escola tem sido o veículo de projeção de padrões e modelos que impedem o verdadeiro conhecimento, privilegiando um conhecimento dado e assimilado pela ordem institucional, nem sempre percebido pelos agentes sociais que conduzem o processo educativo" (Gusmão, 2003, p. 92). Com isso, temos que a tarefa de educar não pode mais ser reduzida à simples transmissão de conhecimento de uma maneira pretensamente imparcial e/ou homogênea, devendo também instigar o exercício do pensamento.

Para viabilizar essa proposta, porém, é preciso que deixemos de lado a perversa ilusão de uma igualdade que, orientada pela perspectiva da "tábula rasa", simplesmente desconsidera as diferenças oriundas das trajetórias individuais de cada aluno. Em outros termos, afirma Valente (2003), a questão é acabar de vez com o efeito retórico de um pragmatismo utópico que, mantendo as críticas sociais fora dos muros da escola - como se as desigualdades, conflitos e injustiças fossem simplesmente neutralizados no contexto da sala de aula -, enquadra sob um mesmo rótulo de "estudantes" pessoas das mais diferentes origens, credos ou classes sociais sem que as influências de tais traços sejam levadas em conta na qualidade do aprendizado desses sujeitos.

Em contrapartida, complementa Gusmão (2003), também é ingênuo achar que se "salva" o ensino simplesmente pelo reconhecimento da alteridade. Aqui, o principal risco que corremos é o da reificação, explicando as diferenças de desempenho por supostas "essências" inerentes a cada um que, assim, se torna o que é por causa da sua cultura e ponto final. ${ }^{8}$ Portanto:

8 Diante do perigo representado por esse multiculturalismo absoluto que, em última instância, significa a recusa antidemocrática do outro, Valente (2003) destaca o poderio criativo do con-
Nem a igualdade absoluta, nem a diferença relativa são efetivamente adequadas para compreender e solucionar o problema da diversidade social e cultural. Nisso residem o paradoxo e o desafio de nossas práticas e propostas educativas. [...] Nessa medida, a escola, mais que um espaço de socialização, torna-se um espaço de sociabilidades, ou seja, um espaço de encontros e desencontros. (Gusmão, 2003, p. 94)

Como se pode perceber, faz-se presente em uma mesma escola a dialética entre a tendência à homogeneização institucional e a prática cotidiana da diferença - que se reflete nas negociações de sentido entre sujeitos com distintas histórias de vida. Uma implicação direta de tal constatação é que não cabe mais ao professor perceber os estudantes apenas como seres de cognição, mas também como seres socioculturais, enigmas em constante transformação.

Tal ampliação de horizontes pode e deve levar o educador a um deixar-se surpreender, a novas atitudes que efetivamente façam girar a roda do conhecimento. Por exemplo, sugere Valente (2003), devolvendo ao discurso veiculado pela escola o uso social (geralmente mantido à sombra) dos conhecimentos ali transmitidos. Eis aí uma lição que, posta em prática, certamente seria premiada com louvor por mestres como Bronislaw Malinowski e Paulo Freire.

\section{Referências bibliográficas}

ASSMANN, Hugo. Metáforas novas para reencantar a educação: epistemologia e didática. 2. ed. Piracicaba: Editora UNIMEP, 1998.

BRANDÃO, Carlos R. Casa de escola. Campinas: Papirus, 1983. DURHAM, Eunice R. (Org.). Bronislaw Malinowski. São Paulo: Ática, 1986.

flito entre o singular e o universal: "Isso porque a escola não pode renunciar à inculcação de regras e convenções sociais da modernidade ocidental capitalista, da qual é fundadora e guardiã, em nome do relativismo cultural que proteja os indivíduos de uma violência e de uma imposição arbitrária que lhes é feita” (p. 42). 
A reconstituição da realidade: um estudo sobre a obra etnográfica de Bronislaw Malinowski. São Paulo: Ática, 1978. FIRTH, Raymond. Man and culture: an evaluation of the work of Bronislaw Malinowski. London: Routledge \& Kegan Paul, 1960. FOOTE-WHYTE, William. Treinando a observação participante. In: GUIMARÃES, Alba Zaluar (Org.). Desvendando máscaras sociais. Rio de Janeiro: Francisco Alves, 1975. p. 77-86.

FREIRE, Paulo. Cartas à Cristina. 2. ed. São Paulo: Editora da UNESP, 2003

Pedagogia da autonomia: saberes necessários à prática educativa. 14. ed. São Paulo: Paz e Terra, 1996.

. Pedagogia do oprimido. 41. ed. São Paulo: Paz e Terra, 2002.

GADOTTI, Moacir (Org.). Paulo Freire: uma biobibliografia. São Paulo: Cortez, 1996

GEERTZ, Clifford. The interpretation of cultures. New York: Basic Books, 1977.

GUSMÃO, Neusa M. Antropologia e educação: origens de um diálogo. Cadernos CEDES, n. 43, p. 8-25, 1997.

Os desafios da diversidade na escola. In: GUSMÃO,

Neusa M. (Org.). Diversidade, cultura e educação: olhares cruzados. São Paulo: Biruta, 2003. p. 83-105.

GUIMARÃES, Alba Zaluar. A máquina e a revolta: organizações populares e o significado da pobreza. São Paulo: Brasiliense, 1985.

HARRIS, Marvin. The rise of anthropological theory. New York: Thomas Y. Crowell, 1968.

MALINOWSKI, Bronislaw C. Argonautas do Pacífico Ocidental. Tradução Anton P. Carr. São Paulo: Abril Cultural, 1976.

. Uma teoria científica da cultura. Tradução José Auto.

2. ed. Rio de Janeiro: Zahar, 1970.

MCLAREN, Peter; LEONARD, Peter (Orgs.). Paulo Freire: a critical encounter. London; New York: Routledge, 1996.
SEEGER, Anthony. Os índios e nós: estudos sobre as sociedades tribais brasileiras. Rio de Janeiro: Campus, 1980.

VALENTE, Ana Lúcia. Conhecimentos antropológicos nos parâmetros curriculares nacionais: para uma discussão sobre a pluralidade cultural. In: GUSMÃO, Neusa M. (Org.). Diversidade, cultura e educação: olhares cruzados. São Paulo: Biruta, 2003. p. 17-46. Usos e abusos da antropologia na pesquisa educacional. Pro-Posições, v. 7, n. 2 (20), p. 54-64, 1996.

VOGET, Fred. A history of ethnology. New York: Holt, Rinehart \& Winston, 1975.

MAURICIO RODRIGUES DE SOUZA, mestre em antropologia social pela Universidade Federal do Pará (UFPA), é professor assistente do Departamento de Psicologia Social e Escolar dessa mesma universidade, realizando atualmente doutoramento em psicologia na Universidade de São Paulo (USP). Tem como principal área de interesse a busca de um diálogo profícuo entre a psicanálise e a antropologia, particularmente no que se refere à relação entre subjetividade e método nos campos de atuação profissional dessas duas disciplinas. Últimas publicações: "Ser carismático": as várias faces de um movimento religioso (Antropologia Portuguesa, v. 20/21, p. 59-87, 2004); Homens do mundo versus homens de Deus: o individualismo na Renovação Carismática Católica (Teoria \& Sociedade, v. 11, n. 2, p. 90-109, 2003); Teoria evolucionista e psicanálise: ressonâncias? (Pulsional-Revista de Psicanálise, n. 167, p. 57-65, 2003). Pesquisa atual: "Experiência do Outro, estranhamento de Si: a psicanálise e a dimensão afetiva da pesquisa etnográfica”. E-mail: mrodri@usp.br

Recebido em fevereiro de 2006 Aprovado em julho de 2006 
Mauricio Rodrigues de Souza

Por uma educação antropológica: comparando as idéias de Bronislaw Malinowski e Paulo Freire

O presente trabalho analisa as idéias de Malinowski e Paulo Freire, propondo algumas proximidades entre a antropologia e a pedagogia. Dentre as possibilidades resultantes de tal encontro, uma certamente merece destaque: a recomendação de que antropólogos e professores respeitem sempre o "saber-fa- 
zer" comunitário e previamente adquirido por seus respectivos outros, alunos ou "nativos", enquanto um verdadeiro ponto de partida para a construção da ciência. Desta maneira, pode-se pensar que em ambas as disciplinas o conhecimento caminha junto a um respeito pela alteridade, lição esta que elas devem partilhar não somente com outras áreas do saber, mas especialmente com a comunidade mais ampla.

Palavras-chave: educação; antropologia; conhecimento e alteridade

For an anthropological education: comparing the ideas of Bronislaw

\section{Malinowski and Paulo Freire}

This article analyses the ideas of Malinowski and Paulo Freire proposing some proximities between anthropology and pedagogy. Among the possibilities resulting from such a meeting, one certainly deserves special attention: the recommendation that anthropologists and teachers should always respect the community knowledge previously acquired by students and "natives" as the real starting point for the construction of science. In this way, it is possible to consider that in both disciplines knowledge be associated with a respect for alterity, a lesson they must share not only with other disciplines, but especially with the wider community. Key words: education; anthropology; knowledge; alterity

Por una educación antropológica: comparando las ideas de Bronislaw Malinowski y Paulo Freire

El presente trabajo analiza las ideas de Malinowski y Paulo Freire, proponiendo algunas proximidades entre la antropología y la pedagogía. Entre las posibilidades resultantes de tal encuentro, una ciertamente merece destaque: la recomendación de que antropólogos y profesores respeten siempre el "saber-hacer" comunitario y previamente adquirido por sus res- pectivos otros, alumnos o "nativos", como un verdadero punto de partida para la construcción de la ciencia. De esta forma se puede pensar que en ambas disciplinas el conocimiento camina junto a un respeto por la alteridad, lección ésta que ellas deben compartir no solamente con otras áreas del saber, mas especialmente con la comunidad más amplia.

Palabras claves: educación; antropología; conocimiento y alteridad 